\section{Zinc-ing about diabetes}

\section{By Kai-Jye Lou, Senior Writer}

ZNT8 burst onto the scene in 2007 as a promising target for type 2 diabetes, and follow-up studies suggested that stimulating the zinc transporter protein could have therapeutic benefit. ${ }^{1,2}$ But a new study suggests that the preferred approach might be to inhibit the target. ${ }^{3}$

Because of the conflicting data, researchers say that more studies are needed to flesh out the functional consequences of expression of ZNT8 (solute carrier family 30 zinc transporter member 8; SLC30A8) and its variants before embarking on drug discovery efforts.

Pfizer Inc. is spearheading a collaborative effort to get such studies under way through its membership in the recently launched Accelerating Medicines Partnership (AMP), which is a public-private partnership to identify and validate disease targets in four disease areas including type 2 diabetes. ${ }^{4}$

ZNT8 is selectively expressed in islet $\beta$ cells. ${ }^{5}$ Interest in the transporter protein as a type 2 diabetes target emerged when four separate genomewide association studies suggested that a SNP variant in the gene resulted in a missense mutation in ZNT8 that was associated with increased risk for the disease. ${ }^{6-9}$

Additional studies suggested that the missense mutation caused a loss of function, although it was never conclusively shown because nobody ever carried out the necessary experiments to fully characterize how the mutation affects ZNT8's function.

Nevertheless, the studies associated the variant with impaired insulin and glucose regulation, ${ }^{10-12}$ and the collective body of data on the functional consequences of the ZNT8 missense variant have generally supported the case for stimulating the zinc transporter's activity to treat type 2 diabetes.

The new genetic study from a group of industry and academic researchers suggests a set of newly identified truncating mutations
"Our goal now is to understand mechanistically the consequences of knocking down this gene."

- Jeff Trimmer, Pfizer Inc.

\section{Truncated}

The team's genotype analysis of about 150,000 individuals across multiple population cohorts identified 12 different ZNT8 variants that encoded a truncated version of the ZNT8 protein.

As a group, carriers of these protein-truncating mutations had $65 \%$ decreased risk of type 2 diabetes compared with noncarriers $\left(p=1.7 \times 10^{-6}\right)$.

Moreover, a cohort of Icelandic individuals showed that carriers of one of the mutations had lower nonfasting glucose levels than noncarriers $\left(p=4.6 \times 10^{-4}\right)$. That finding suggested that the mutant ZNT8 is associated with improved glucose tolerance.

Cell line studies suggested that the two most commonly identified protective mutations resulted in the expression of an unstable variant of the transporter protein, which in turn suggests that decreased ZNT8 activity is associated with lower diabetes risk.

Results were published in Nature Genetics. The study was led by researchers at the Broad Institute of MIT and Harvard, Massachusetts General Hospital, Lund University and Pfizer. deCode genetics ehf (now part of Amgen Inc.), the Genetics of Type 2 Diabetes (GoT2D) consortium and the Type 2 Diabetes Genetic Exploration by Next-Generation Sequencing in Multi-Ethnic Samples (T2D-GENES) consortium also contributed to the study.

"The question we have been trying to answer in our studies is what genetic factors protect or make us susceptible to diabetes," said Kári Stefánsson, the co-corresponding author on the study and chairman and CEO of Amgen's deCode unit. He said that such information could be used by drug developers to better understand how to treat the disease.

"The fact that we see truncated proteins resulting from these gene variants and proteins with decreased activity points us in a direction that loss-of-function mutations are protective in human subjects," added Ann-Marie Richard, a coauthor and principal scientist in Pfizer's Cardiovascular and Metabolic Diseases (CVMED) research unit.

\section{Determining functional consequences}

Stefánsson said that the results from the earlier studies and his new paper might not be in direct conflict. Instead, he said that the missense mutation found in the earlier studies could actually be a gain of function rather than a loss of function.

Under that scenario, the missense mutation's gain of function would logically produce results that are the opposite of the newly found loss-of-function truncating mutations.

At the end of the day, additional studies in ZNT8 that cause a loss of function that protects against diabetes rather than increasing the risk.

Thus, the new data suggest that inhibiting rather than stimulating ZNT8 could help treat type 2 diabetes. in human cell lines and subjects are needed to characterize the functional consequences of multiple ZNT8 variants. that AMP will take up the mantle of running such studies. The NIH
Tim Rolph, VP and CSO of the CVMED research unit at Pfizer, said 
launched AMP last month, and Pfizer is one of the initiative's industry partners.

The type 2 diabetes arm of the partnership has a 5-year budget of $\$ 58.4$ million.

"Our goal now is to understand mechanistically the consequences of knocking down this gene," said Jeff Trimmer, executive director and group leader in Pfizer's CVMED research unit.

Rolph and Trimmer are both coauthors on the Nature Genetics study.

Richard said that it will be necessary to phenotypically characterize the metabolic differences between carriers and noncarriers of the identified ZNT8 variants, for example, by looking at circulating levels of insulin, proinsulin and glucagon.

To help address some known inconsistencies between mouse and human data, Rolph said that researchers should generate and characterize heterozygous $Z n t 8$ knockouts and see how the phenotype compares with that of human carriers of the protective $Z N T 8$ variants.

Homozygous Znt8 knockout mice show a broad spectrum of phenotypes that vary according to gender and genetic backgrounds. ${ }^{13,14}$ These phenotypes range from having modest hyperglycemia and altered insulin secretion to having normal glucose and insulin regulation.

Guy Rutter, a professor and head of the section of cell biology at Imperial College London, added that it will be important to evaluate the effects of overexpressing various ZNT8 variants in preclinical models. Those studies, he said, would help resolve the apparent discrepancy between the conclusions of the current study and those that preceded it.

Rutter also wanted to see additional sequencing studies around the area of the genome in which the identified mutations occur to determine if they also affect other genes.

Separately, Stefánsson said that deCode has been recruiting known carriers of ZNT8 variants over the last few months to participate in studies to characterize the effects of the variants on glucose tolerance and insulin sensitivity.

Amgen spokesperson Kristen Davis said that at this time it is still too early to discuss the company's future research plans with ZNT8. Amgen currently has the fusion protein AMG 876 in Phase I testing to treat type 2 diabetes. Details of the compound and its target are undisclosed.

The findings reported in Nature Genetics are unpatented.

Lou, K.-J. SciBX 7(10); doi:10.1038/scibx.2014.276

Published online March 13, 2014

\section{REFERENCES}

1. Nicolson, T.J. et al. Diabetes 58, 2070-2083 (2009)

2. Tamaki, M. et al. J. Clin. Invest. 123, 4513-4524 (2013)

3. Flannick, J. et al. Nat. Genet.; published online March 2, 2014; doi:10.1038/ng.2915

Contact: David Altshuler, Broad Institute of MIT and Harvard, Cambridge, Mass.

e-mail: altshuler@molbio.mgh.harvard.edu

Contact: Kári Stefánsson, deCode genetics ehf and Amgen Inc. Reykjavik, Iceland

e-mail: kstefans@decode.is

4. Fishburn, C.S. SciBX 7(8); doi:10.1038/scibx.2014.215

5. Chimienti, F. et al. Diabetes 53, 2330-2337 (2004)

6. Sladek, R. et al. Nature 445, 881-885 (2007)

7. Diabetes Genetics Initiative of Broad Institute of Harvard and MIT, Lund University, and Novartis Institutes of BioMedical Research et al. Science 316, 1331-1336 (2007)

8. Zeggini, E. et al. Science 316, 1336-1341 (2007)

9. Scott, L.J. et al. Science 316, 1341-1345 (2007)

10. Steinthorsdottir, V. et al. Nat. Genet. 39, 770-775 (2007)

11. Kirchhoff, K. et al. Diabetologia 51, 597-601 (2008)

12. Xu, K. et al. Diabetes Res. Clin. Pract. 91, 195-202 (2011)

13. Pound, L.D. et al. PLoS One 7, e40972; published online July 19, 2012; doi:10.1371/journal.pone.0040972

14. da Silva Xavier, G. et al. J. Diabetes Res. 2013, 906590; published online April 11, 2013; doi:10.1155/2013/906590

COMPANIES AND INSTITUTIONS MENTIONED

Amgen Inc. (NASDAQ:AMGN), Thousand Oaks, Calif. Broad Institute of MIT and Harvard, Cambridge, Mass. Imperial College London, London, U.K.

Lund University, Lund, Sweden

Massachusetts General Hospital, Boston, Mass.

National Institutes of Health, Bethesda, Md.

Pfizer Inc. (NYSE:PFE), New York, N.Y. 